\title{
Possible ameliorating effects of Glycyrrhiza Glabra (Licorice) on the sperm parameters in rats under high fat diet
}

\author{
Mehrdad Ghorbanlou ${ }^{1}$, Somaye Rostamkhani ${ }^{2}$, Saeed Shokri ${ }^{3}$, Sanaz Mahmazi ${ }^{4}$, \\ Ramazan Falla ${ }^{5}$, Fateme Mor Adi ${ }^{3}$, Reza NejatbaKhsh ${ }^{3}$
}

${ }^{1}$ Department of Anatomical Sciences, School of Medicine, Iran University of Medical Sciences, Tehran, Iran; ${ }^{2}$ Department of Animal Physiology, Zanjan Islamic Azad University of Medical Sciences; Zanjan, Iran; ${ }^{3}$ Department of Anatomical Sciences, School of Medicine, Zanjan University of Medical Sciences, Zanjan, Iran; ${ }^{4}$ Department of Biology and Genetics, Zanjan Islamic Azad University of Medical Sciences; Zanjan, Iran; ${ }^{5}$ Department of Biostatistics and Epidemiology, School of Medicine, Zanjan University of Medical Sciences, Zanjan, Iran E-mail:reza_nejat@yahoo.com

Objectives. Adverse effects of obesity, which is caused by an imbalance between the energy intake and expenditure, on the male reproductive system have been reported. Considering the anti-obesity effect of Glycyrrhiza Glabra (GC), we conducted this study to elucidate whether it can ameliorate the sperm parameters.

Methods. In this experimental study, male Wistar rats of 6-8 weeks old were divided into four groups: control, high fat diet (HFD), GC50 (HFD plus $50 \mathrm{mg} / \mathrm{kg} \mathrm{GC} \mathrm{extract),} \mathrm{and} \mathrm{GC100} \mathrm{(HFD}$ plus $100 \mathrm{mg} / \mathrm{kg}$ GC extract). During the 16 weeks of the study course, the rats consumed the extract through gavage, daily. Body mass index (BMI), body weight gain, serum lipid profile, leptin concentration, and sperm parameters were investigated. Data were analyzed by one-way analysis of variance (ANOVA) (post hoc Tukey) to express the significance of mean differences of variables between groups, and linear regression test was used to express the correlation model of variables. Both tests were performed by SPSS software; $\mathrm{p} \leq 0.05$ was considered significant.

Results. BMI was significantly decreased by the GC50 and GC100 groups compared to HFD group. GC50 group considerably decreased leptin level compared to HFD group. A significant positive correlation between leptin and triglyceride levels was evident. GC50 and GC100 extensively increased the total sperm motility and ameliorated the sperm abnormal morphology and count compared to HFD group.

Conclusion. Glycyrrhiza Glabra extract may exert its ameliorating effects on the sperm parameters through its anti-obesity impact. Both doses of the extract were effective, however, the GC100 was more effective in improving the sperm parameters.

Key words: high-fat diet, Glycyrrhiza Glabra, sperm, leptin, rat

Obesity is the result of an excessive energy intake compared to its expenditure (Sikaris 2004). It can adversely affect most systems of the body and cause several medical problems such as coronary artery disease, hypertension, type 2 diabetes, and many forms of cancer (Mitchell et al. 2011). If common trends continue, an estimation of $38 \%$ and $20 \%$ of the world's population will be overweight and obese, respectively by 2030 (Kelly et al. 2008). Alterations in body mass index (BMI) and serum lipid profile including total cholesterol (TC), triglyceride (TG), high-density lipoprotein (HDL), and low-density lipoprotein (LDL) are factors indicating obesity (Kelishadi et al. 2012; Bibiloni et al. 2016). 
Studies based on animal models have shown that high fat diet leads to a reduction of normal sperm, sperm motility defect, testosterone concentration reduction, glucose homeostasis alterations, and leptin insensitivity (Fernandez et al. 2011; Teerds et al. 2011). Although obese men are not always confronted by impaired fertility, $80 \%$ of men referring to the infertility clinics can be categorized as either overweight or obese, which indicates a relationship between the obesity and fertility problems (Bakos et al. 2011).

Glycyrrhiza Glabra, also known as Licorice, is a widely growing medicinal herb distributed in Mediterranean and the south-west Asia regions (Namazi et al. 2017). The leaves include 4-7 pairs of oblong, elliptical leaflets, which are compound and imparipinnate. The flowers' shape are narrow, which are borne in axillary spikes and the color is lavender or violet (Kaur et al. 2013). It contains flavonoids, glycyrrhizin, beta-glycyhrritinic acid, glabridin, chalcones, sterols, isoflavones, amino acids, and triterpenoidsaponins (Khanahmadi et al. 2013). It had been used as an antiinflammatory, anti-bacterial, anti-viral, antioxidant, anti-mutagenic, and anti-asthmatic agent (Kaur et al. 2013; Khanahmadi et al. 2013). Anti-obesity effects of this herb have been reported in recent years, as well (Aoki et al. 2007; Kamisoyama et al. 2008).

Considering the anti-obesity effects of Glycyrrhiza Glabra, we conducted this study to elucidate its role in altering BMI, leptin level, serum lipid profile, and how it can ameliorate the adverse effects of obesity on sperm count, motility, and morphology of rats under high fat diet. We also looked for correlations between BMI, leptin level, serum lipid profile, and sperm parameters.

\section{Materials and methods}

Animals and diets. In this experimental study, 32 male Wistar rats at the age of 6-8 weeks, weighing 180-210 g were housed under environmentally controlled conditions in $23-25^{\circ} \mathrm{C}$ and a $12 / 12-\mathrm{h}$ light/dark cycle and were accessed to drinking water ad libitum. Animals were divided into 4 groups, each containing 8 rats: Control group (normal diet including $65 \%$ carbohydrates, $20.3 \%$ proteins, $5 \%$ fat, $3.7 \%$ salt mixture, $5 \%$ fiber, and $1 \%$ vitamin mixture, plus the solvent of GC extract which is distilled water as placebo administered through gavage), high fat diet (HFD) group (24\% carbohydrates, $20.3 \%$ proteins, $46 \%$ fat, $3.7 \%$ salt mixture, $5 \%$ fiber, and $1 \%$ vitamin mixture) (Kim et al. 2005), GC50 (HFD plus $50 \mathrm{mg} / \mathrm{kg}$ Glycyrrhiza Glabra hydroethanolic extract), GC100 (HFD plus $100 \mathrm{mg} / \mathrm{kg}$ Glyc- yrrhiza Glabra hydroethanolic extract). Selected doses of the extract were in accordance to previous studies (Kamisoyama et al. 2008; Malik and Sharma 2011). During the study course, 16 weeks, animals consumed the extract through gavage, daily (once a day). For preparing the extract powder as a solution to feed animals, the proper amount of extract powder was solved in distilled water. Concentrations were $5 \mathrm{mg} / \mathrm{ml}$ for GC50 group and $10 \mathrm{mg} / \mathrm{ml}$ for GC100 group. We started to gavage by approximately $1 \mathrm{ml}$ of solution and gradually increased the volume when animals gained weight. Animals were treated in accordance with ethics committee of laboratory animals of Zanjan University of Medical Sciences. Experiments performed on animals were also in accordance with national guidelines and protocols of Institutional Animal Ethics Committee.

Preparation of hydroethanolic extract of Glycyrrhiza Glabra. Glycyrrhiza Glabra (GC) roots were provided by a local herb store, and confirmed by the Pharmacognosy Department at Zanjan University of Medical Sciences. Using an electric grinder, the roots were ground into powder. To prepare the hydroethanolic extract, $500 \mathrm{~g}$ of GC powder was added to a decanter (Zhejiang, China). Eighty percent ethanol (Razi Yeast and Alcohol Co., Iran) was added to cover all the powder. After $24 \mathrm{~h}$, the solvent was collected. This process was repeated till the solvent color became clear. The collected solvents were filtered and evaporated under reduced pressure by using a rotary evaporator apparatus (Zhengzhou Keda Machinery and Instrument Equipment Co, China). The yield of hydroethanolic extract was 10\% (10 g of GC extract/100 g of powdered GC roots).

Food intake, BMI, weight gain, omental and renal fat, serum lipid profile, and leptin measurements. Food intake was measured weekly for every cage containing 8 rats, and the average food intake after the course of study was reported in g/week. The final body weight (kg) and height (nose to anus, m) was measured and the BMI was reported as the weight divided by square of height $\left(\mathrm{kg} / \mathrm{m}^{2}\right)$, the final body weight gain was reported, as well. At the end of the study, animals were dissected under deep ketamine $(50 \mathrm{mg} / \mathrm{kg})$ and xylazine $(5 \mathrm{mg} / \mathrm{kg})$ anesthesia (Struck et al. 2011). Then omental and renal fat were removed and weighed separately. Blood samples were collected from the heart, centrifuged at $1000 \times \mathrm{g}$, at $4{ }^{\circ} \mathrm{C}$ for $10 \mathrm{~min}$ in order to isolate the serum. Serum lipid profile including TG, TC, HDL, and LDL were measured through enzymatic method by the specific kits (Diasys Diagnostics Systems, GmbH, Germany). Leptin concentration was measured using commer- 
cially available enzyme-linked immunosorbent assay (ELISA) kits specific for rats (Millipore, St. Charles, MO, USA).

Evaluation of sperm motility, count and morphology. Caudal part of the epididymis was separated from the testes and after being punctured by needle, immersed in $5 \mathrm{ml}$ of Ham's F10 medium and incubated for $10-15 \mathrm{~min}$ at $37^{\circ} \mathrm{C}$. One drop $(50 \mu \mathrm{l})$ of sperm suspension was placed on a pre-warmed slide and a cover slip was placed over the droplet. For sperm motility evaluation (Momeni and Eskandari 2012), 10 microscopic fields were observed under light microscope (Motic BA410, Kowloon, Hong Kong) at 400× magnification. Progressive sperms (moving across the microscopic field), non-progressive sperms (flagella is motile but the sperm is standing still), and immotile sperms (no movement at all) were counted. Non-progressive sperms plus progressive sperms were reported as total sperm motility. The count and morphological assessments were done according to Shokri et al. (2010). Briefly, for counting assessments, $20 \mu$ of prepared solution was mixed with an equal volume of $0.05 \%$ eosin-Y and following 2 min incubation at room temperature, slides were viewed by light microscope at $400 \times$ magnification. Pink appearance indicated dead spermatozoa and unstained spermatozoa were alive. For morphological evaluation, 100 spermatozoa of slides containing prepared solution stained with $1 \%$ eosin- $Y / 5 \%$ nigrosine were assessed.
Statistical analysis. To check the normal distribution of data, Kolmogorov-Smirnov test was applied. After confirming the normal distribution of data, parametric tests were used for data analysis. For analyzing the relationship of variants including BMI, weight of organs' fat, food intake, serum lipid profile, leptin level, and sperm parameters among the study groups, data were analyzed by one-way analysis of variance (ANOVA) and post-hoc Tukey test. For expressing the correlation of leptin level and BMI, and serum lipid profile, linear regression test was performed. Furthermore, for expressing the correlation between leptin level, BMI, and serum lipid profile, and the sperm parameters another linear regression test was applied. To express whether there is a significant difference between the initial and final BMI of study groups, we used paired sample t-test. All the analyses were carried out by SPSS software, version 16 (SPSS, Inc., Chicago, IL, USA). Data were expressed as mean values \pm standard deviation (SD). Value $p \leq 0.05$ was considered statistically significant.

\section{Results}

Food intake, BMI, weight gain, omental and renal fat measurements. Food intake showed significant increase in GC100 group compared to HFD $(\mathrm{p}=0.04)$, and control $(\mathrm{p}=0.05)$ groups. Initial and final BMIs were reported. No significant difference

Table 1

Omental and renal fat weights, weight gain, BMI, leptin level, and serum lipid profile in study groups.

\begin{tabular}{|c|c|c|c|c|}
\hline \multirow{2}{*}{ Parameter } & \multicolumn{4}{|c|}{ Group } \\
\hline & Control & HFD & GC50 & GC100 \\
\hline Food intake (g/week) & $351.33 \pm 15.37$ & $353.67 \pm 25.1$ & $392.42 \pm 7.54$ & $397.33 \pm 15.5^{* \#}$ \\
\hline Initial BMI $\left(\mathrm{kg} / \mathrm{m}^{2}\right)$ & $5.15 \pm 0.15$ & $4.97 \pm 0.16$ & $5.07 \pm 0.17$ & $5.23 \pm 0.18$ \\
\hline Final BMI $\left(\mathrm{kg} / \mathrm{m}^{2}\right)$ & $5.8 \pm 0.17$ & $6.46 \pm 0.19^{* a}$ & $5.77 \pm 0.07^{\# \mathrm{~b}}$ & $5.84 \pm 0.21^{\# \mathrm{c}}$ \\
\hline Weight gain (g) & $108.3 \pm 2.31$ & $133.52 \pm 12.68$ & $118.2 \pm 4.66$ & $105.6 \pm 2.57^{\#}$ \\
\hline Left renal fat (g) & $0.62 \pm 0.09$ & $0.86 \pm 0.18$ & $0.59 \pm 0.06$ & $0.74 \pm 0.07$ \\
\hline Right renal fat (g) & $0.65 \pm 0.06$ & $0.81 \pm 0.18$ & $0.65 \pm 0.05$ & $0.7 \pm 0.09$ \\
\hline Omental fat (g) & $1.03 \pm 0.16$ & $1.59 \pm 0.23^{*}$ & $0.99 \pm 0.04^{\#}$ & $1.08 \pm 0.11^{\#}$ \\
\hline $\mathrm{TG}(\mathrm{ng} / \mathrm{ml})$ & $51.75 \pm 4.23$ & $85.8 \pm 10.27^{*}$ & $67.75 \pm 5.62$ & $75.06 \pm 6.43$ \\
\hline $\mathrm{TC}(\mathrm{mg} / \mathrm{dl})$ & $45.25 \pm 2.34$ & $62.75 \pm 4.1^{*}$ & $61.50 \pm 3.17^{*}$ & $60.75 \pm 0.85^{*}$ \\
\hline HDL (mg/dl) & $13.5 \pm 1.06$ & $19.2 \pm 1.74^{*}$ & $19.250 .75^{*}$ & $20.04 \pm 0.46^{*}$ \\
\hline $\mathrm{LDL}(\mathrm{mg} / \mathrm{dl})$ & $22.07 \pm 0.84$ & $30.5 \pm 1.27^{*}$ & $31.03 \pm 2.11^{*}$ & $29.25 \pm 0.75^{*}$ \\
\hline Leptin (ng/dl) & $673.58 \pm 68.39$ & $1152.27 \pm 132.6$ & $561.97 \pm 57.13^{\#}$ & $767.14 \pm 108.5$ \\
\hline
\end{tabular}

Values are reported as mean \pm S.D. ${ }^{*} p=0.04$ vs. Control group; $\# p=0.05$ vs. HFD group; ${ }^{a} p=0.002$ final BMI of HFD vs. initial BMI of HFD group; ${ }^{b} \mathrm{p}=0.02$ final BMI of GC50 group vs. initial BMI of GC50 group; ${ }^{c} \mathrm{p}=0.002$ final BMI of GC100 group vs. initial BMI of GC100 group. Abbreviations: BMI - body mass index; TG - triglyceride; TC - total cholesterol; HDL - high-density lipoprotein; LDL - low-density lipoprotein; GC - Glycyrrhiza Glabra; HFD - high fat diet; GC50 - HFD plus 50 mg/kg GC extract; GC100 - HFD plus $100 \mathrm{mg} / \mathrm{kg}$ GC extract. 
was evident among initial BMIs of the study groups. There was a significant increase in final BMI in HFD group compared with the initial BMI in HFD group $(\mathrm{p}=0.002)$, final BMI in GC50 group compared with the initial BMI in GC50 group $(p=0.02)$, and final BMI in GC100 group compared with the initial BMI in GC100 group $(p=0.05)$. There was a significant difference among final BMIs of study groups showing increased final BMI in high fat diet group compared to control ( $p=0.05)$. GC50 and GC100 groups significantly decreased the final BMI compared to HFD group ( $\mathrm{p}=0.04)$ (Table 1$)$. GC100 group significantly reduces the body weight gain compared to HFD group $(\mathrm{p}=0.04)$.

Right and left renal fat weights were increased in HFD group compared to other groups but the alterations were not significant. Omental fat weight was significantly increased in HFD group compared to the control group $(p=0.04)$. GC50 and GC100 groups decreased the omental fat weight significantly compared to HFD group ( $\mathrm{p}=0.04)$ (Table 1).

Serum lipid profile and leptin measurements. HFD significantly increased TG, TC, HDL, and LDL in comparison to control group $(\mathrm{p}=0.05,0.01,0.03$, 0.01 , respectively). Although GC50 group decreased TG in comparison to HFD, it was not significant. There was no significant alteration of serum lipid profile in treatment groups compared to HFD group (Table 1).

According to Table 1, leptin concentration was considerably decreased in GC50 group compared to HFD group $(\mathrm{p}=0.02)$. GC100 group did not decrease the leptin level extensively.

Sperm motility, count and morphology. Total sperm motility was significantly decreased in HFD group $(24.95 \pm 3.35)$ compared to control group $(57.36 \pm 4.44)(p=0.000)$. GC50 and GC100 groups significantly ameliorated total motility (52.9 \pm 2.86 and 55.94 \pm 3.71 , respectively) compared to HFD group ( $\mathrm{p}=0.01$ and $\mathrm{p}=0.000$, respectively) (Figure 1 ). Although progressive motility of sperm was not significantly affected by the HFD and extract treatments, it was decreased by HFD in comparison to control group, and extract treatments increased it in comparison to HFD.

Sperm abnormal morphology was sharply affected in HFD (40.62 \pm 2.35$),$ GC50 (30.84 \pm 4.23$)$, and GC100 (29.38 \pm 1.54$)$ when compared to control group $(10.20 \pm 0.69) \quad(p=0.000)$. GC100 significantly decreased the abnormal morphology compared to HFD group $(\mathrm{p}=0.02)$ (Figure 2).

Sperm count was influenced considerably by 100 $\mathrm{mg} / \mathrm{kg}$ dose of extract, showing a significant increase

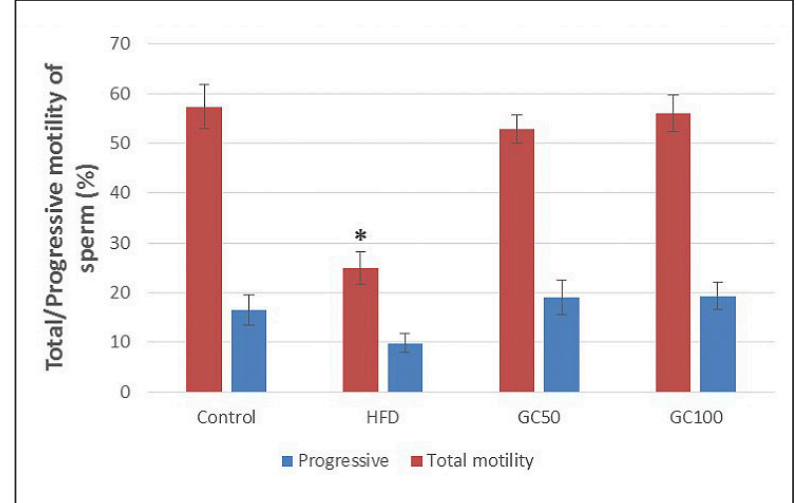

Figure 1. Sperm motility in study groups. HFD - high fat diet; GC50 - HFD plus $50 \mathrm{mg} / \mathrm{kg}$ GC extract; GC100 - HFD plus 100 mg/kg GC extract; GC - Glycyrrhiza Glabra. Data are reported as mean \pm S.D. ${ }^{*} \mathrm{p}=0.001$ for HFD group vs. Control, GC50 and GC100 groups.

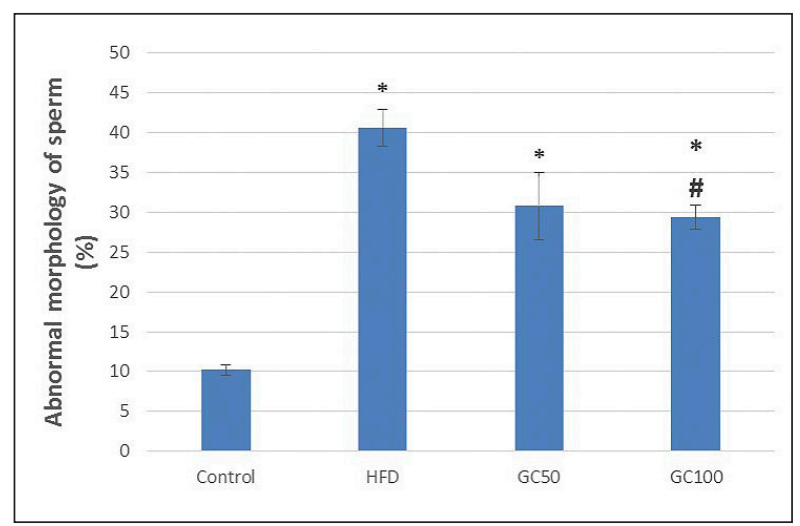

Figure 2. Abnormal morphology of sperm in study groups. HFD - high fat diet; GC50 - HFD plus $50 \mathrm{mg} / \mathrm{kg} \mathrm{GC} \mathrm{extract;}$ GC100 - HFD plus 100 mg/kg GC extract; GC - Glycyrrhiza Glabra. Data are reported as mean \pm S.D. ${ }^{*} \mathrm{p}=0.000$ for HFD, GC50 and GC100 groups vs. Control group; ${ }^{p} \mathrm{p}=0.02$ for GC100 group vs. HFD group.

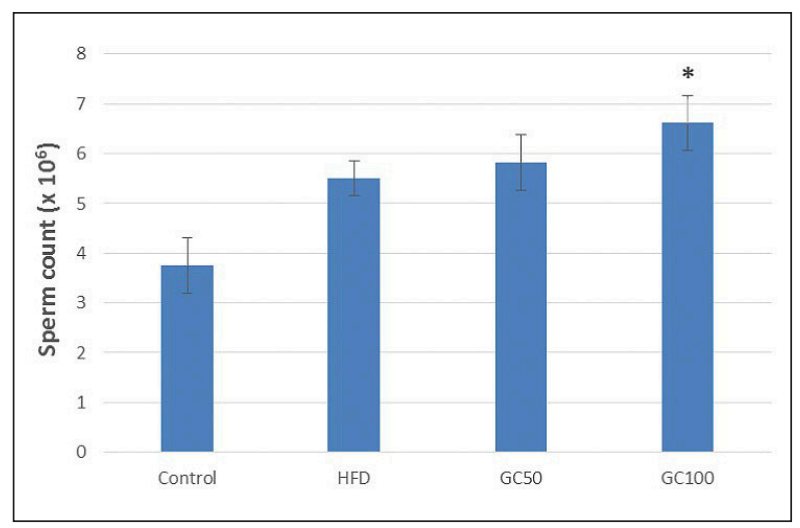

Figure 3. Sperm count in study groups. HFD - high fat diet; GC50 - HFD plus 50 mg/kg GC extract; GC100 - HFD plus 100 mg/kg GC extract; GC - Glycyrrhiza Glabra. Data are reported as mean \pm S.D. ${ }^{*} \mathrm{p}=0.01$ for GC100 group vs. Control group. 
in GC100 group $\left(6.62 \times 10^{6} \pm 0.55\right)$ compared to control group $\left(3.75 \times 10^{6} \pm 0.61\right)(\mathrm{p}=0.01)$ (Figure 3$)$.

Correlation between leptin, BMI, TG, TC, LDL and HDL levels. In order to find out whether leptin level influences BMI, TG, TC, LDL and HDL levels, we assumed leptin as an independent variant and other parameters as dependent variants. According to Table 2, there is a significant positive correlation between leptin level and BMI $(r=0.69 ; \mathrm{p}=0.01)$. In a linear regression model, it can be estimated that there is a $0.001 \mathrm{~kg} / \mathrm{m}^{2}$ increase in BMI per $1 \mathrm{ng} / \mathrm{dl}$ increase in leptin level. It is also estimated that $47 \%$ of the variations in BMI can be explained by leptin level. A significant positive correlation is also estimated between leptin and TG level $(r=0.77 ; p=0.003)$. It can be estimated that there is $0.004 \mathrm{ng} / \mathrm{ml}$ increase in TG level per $1 \mathrm{ng} / \mathrm{dl}$ increase in leptin level. The linear regression model also estimates that $60 \%$ of the variations in TG level can be explained by leptin level. TC, LDL and HDL levels are not significantly correlated with leptin level.

Correlation between leptin, BMI, TG, TC, LDL, and HDL levels and sperm parameters. Assuming the sperm parameters as dependent variants, we used linear regression model to predict how leptin, BMI, TG, TC, LDL and HDL levels can influence sperm parameters. According to Table 3, there is a signifi- cant negative correlation between $\mathrm{BMI}$ and progressive $(r=-0.58 ; p=0.02)$ and total $(r=-0.84 ; p=0.001)$ motility. It means that by $1 \mathrm{~kg} / \mathrm{m}^{2}$ increase in BMI, $12.86 \%$ and $39.11 \%$ decrease in progressive and total motility is estimated, respectively. A significant negative correlation between TG and total motility $(\mathrm{r}=-0.54 ; \mathrm{p}=0.03)$ estimates $0.5 \%$ decrease in total motility per $1 \mathrm{ng} / \mathrm{ml}$ increase in TG level. A significant positive correlation between TG and abnormal morphology $(r=0.60 ; p=0.02)$ estimates $0.43 \%$ increase

Table 2

Linear regression results show how leptin alterations can affect BMI and serum lipid profile.

\begin{tabular}{lcccc}
\hline $\begin{array}{l}\text { Dependent } \\
\text { variables }\end{array}$ & $\mathbf{r}$ & $\mathbf{B}$ & $\mathbf{r}^{2}$ & p-value \\
\hline BMI & $0.69^{*}$ & 0.001 & 0.47 & 0.01 \\
TG & $0.77^{* *}$ & 0.047 & 0.60 & 0.003 \\
TC & 0.5 & 0.015 & 0.28 & 0.07 \\
LDL & 0.51 & 0.005 & 0.26 & 0.09 \\
HDL & 0.39 & 0.006 & 0.07 & 0.20 \\
\hline
\end{tabular}

${ }^{*}$ significant correlation between leptin and BMI; ${ }^{* *}$ significant correlation between leptin and TG. Abbreviations: $r$ - Pearson's correlation coefficient; B - Model coefficient; $r^{2}$ - square of Pearson's correlation coefficient; BMI - body mass index; TG - triglyceride; TC - total cholesterol; LDL - low-density lipoprotein; HDL - high-density lipoprotein.

Table 3

How sperm parameters, as dependent variables, are influenced by leptin, BMI, TG, TC, LDL and HDL parameters, as independent variants

\begin{tabular}{|c|c|c|c|c|c|c|c|c|c|c|c|c|}
\hline \multirow{4}{*}{$\begin{array}{l}\text { Dependent variants } \\
\text { Sperm parameters } \\
\text { Progressive } \\
\text { motility }\end{array}$} & \multicolumn{12}{|c|}{ Independent variants } \\
\hline & \multicolumn{2}{|c|}{ Leptin } & \multicolumn{2}{|c|}{ BMI } & \multicolumn{2}{|c|}{ TG } & \multicolumn{2}{|c|}{$\mathrm{TC}$} & \multicolumn{2}{|c|}{ LDL } & \multicolumn{2}{|c|}{ HDL } \\
\hline & $\mathrm{r}$ & -0.45 & $\mathrm{r}$ & $-0.58^{*}$ & $\mathrm{r}$ & -0.34 & $\mathrm{r}$ & -0.14 & $\mathrm{r}$ & -0.05 & $\mathrm{r}$ & -0.18 \\
\hline & B & -0.01 & B & -12.86 & B & -0.15 & B & -0.13 & B & -0.13 & B & -0.34 \\
\hline & $\mathrm{r}^{2}$ & 0.20 & $r^{2}$ & 0.33 & $r^{2}$ & 0.12 & $\mathrm{r}^{2}$ & 0.02 & $\mathrm{r}^{2}$ & 0.003 & $\mathrm{r}^{2}$ & 0.03 \\
\hline & $\mathrm{p}$ & 0.07 & $\mathrm{p}$ & 0.02 & $\mathrm{p}$ & 0.13 & $\mathrm{p}$ & 0.32 & $\mathrm{p}$ & 0.43 & $\mathrm{p}$ & 0.26 \\
\hline \multirow[t]{4}{*}{ Total motility } & $\mathrm{r}$ & -0.36 & $\mathrm{r}$ & $-0.84^{*}$ & $\mathrm{r}$ & $-0.54^{*}$ & $\mathrm{r}$ & -0.45 & $\mathrm{r}$ & -0.33 & $\mathrm{r}$ & -0.40 \\
\hline & B & -0.04 & B & -39.11 & B & -0.50 & B & -0.88 & B & -1.76 & B & -1.56 \\
\hline & $\mathrm{r}^{2}$ & 0.13 & $r^{2}$ & 0.70 & $r^{2}$ & 0.29 & $r^{2}$ & 0.2 & $r^{2}$ & 0.11 & $r^{2}$ & 0.16 \\
\hline & $\mathrm{p}$ & 0.12 & $\mathrm{p}$ & 0.001 & $\mathrm{p}$ & 0.03 & $\mathrm{p}$ & 0.06 & $\mathrm{p}$ & 0.14 & $\mathrm{p}$ & 0.09 \\
\hline \multirow{4}{*}{$\begin{array}{l}\text { Abnormal } \\
\text { morphology }\end{array}$} & $\mathrm{r}$ & 0.36 & $\mathrm{r}$ & 0.45 & $\mathrm{r}$ & $0.6^{*}$ & $\mathrm{r}$ & $0.77^{*}$ & $\mathrm{r}$ & $0.66^{*}$ & $\mathrm{r}$ & $0.81^{*}$ \\
\hline & B & 0.01 & B & 16.45 & B & 0.43 & B & 1.18 & B & 2.77 & B & 2.47 \\
\hline & $\mathrm{r}^{2}$ & 0.13 & $r^{2}$ & 0.20 & $r^{2}$ & 0.36 & $r^{2}$ & 0.59 & $r^{2}$ & 0.44 & $r^{2}$ & 0.65 \\
\hline & $\mathrm{p}$ & 0.12 & $\mathrm{p}$ & 0.07 & $\mathrm{p}$ & 0.02 & $\mathrm{p}$ & 0.001 & $\mathrm{p}$ & 0.009 & $\mathrm{p}$ & 0.001 \\
\hline \multirow[t]{4}{*}{ Count } & $\mathrm{r}$ & 0.10 & $\mathrm{r}$ & -0.23 & $\mathrm{r}$ & 0.36 & $\mathrm{r}$ & $0.59^{*}$ & $\mathrm{r}$ & $0.63^{*}$ & $\mathrm{r}$ & $0.57^{\star}$ \\
\hline & B & 584 & B & -10840 & B & 33720 & B & 115243 & B & 333080 & B & 223025 \\
\hline & $\mathrm{r}^{2}$ & 0.01 & $r^{2}$ & 0.05 & $r^{2}$ & 0.13 & $r^{2}$ & 0.34 & $r^{2}$ & 0.39 & $r^{2}$ & 0.32 \\
\hline & $\mathrm{p}$ & 0.37 & $\mathrm{p}$ & 0.23 & $\mathrm{p}$ & 0.12 & $\mathrm{p}$ & 0.02 & $\mathrm{p}$ & 0.01 & $\mathrm{p}$ & 0.02 \\
\hline
\end{tabular}

The results of linear regression analysis are reported. ${ }^{\star} \mathrm{p} \leq 0.05$ - indicates the significant correlation between parameters.

Abbreviations: $\mathrm{r}$ - Pearson's correlation coefficient; B - Model coefficient; $\mathrm{r}^{2}$ - square of Pearson's correlation coefficient; $\mathrm{p}$ - $\mathrm{p}$ value; BMI - body mass index; TG - triglyceride; TC - total cholesterol; LDL - low-density lipoprotein; HDL - high-density lipoprotein. 
in abnormal morphology per $1 \mathrm{ng} / \mathrm{ml}$ increase in TG level. A significant positive correlation between TC and abnormal morphology $(\mathrm{r}=0.77 ; \mathrm{p}=0.001)$ estimates $1.18 \%$ increase in abnormal morphology per $1 \mathrm{mg} / \mathrm{dl}$ increase in TC level. TC level is also in a significant correlation with count $(\mathrm{r}=0.59 ; \mathrm{p}=0.02)$ which estimates 115243 sperm increase per $1 \mathrm{mg} / \mathrm{kg}$ increase in TC level. LDL is also in a significant correlation with abnormal morphology $(r=0.66 ; p=0.009)$ and count $(\mathrm{r}=0.63 ; \mathrm{p}=0.01)$ which estimates $2.77 \%$ and 333080 sperm increase in abnormal morphology and count, respectively, per $1 \mathrm{mg} / \mathrm{kg}$ increase in TC level. Finally, HDL is in a significant positive correlation with abnormal morphology $(\mathrm{r}=0.81 ; \mathrm{p}=0.001)$ and count $(\mathrm{r}=0.57 ; \mathrm{p}=0.02)$ which estimates $2.47 \%$ and 223025 sperm increase in abnormal morphology and count, respectively, per $1 \mathrm{mg} / \mathrm{kg}$ increase in HDL level.

\section{Discussion}

Considering the adverse effects of high-fat diet on male reproductive characteristics (Ghanayem et al. 2010; Fernandez et al. 2011; La Vignera et al. 2012), we conducted this study to elucidate whether an anti-obesity substance, Glycyrrhiza Glabra extract, can boost sperm parameters through affecting the leptin, BMI, and serum lipid profile. Many studies have shown positive effects of herbal medicine in reducing weight and normalizing sperm parameters (Rahimi and Ardekani 2013; Monton et al. 2015; Nejatbakhsh et al. 2017). We also reported correlation between leptin, BMI, serum lipid profile, and sperm parameters.

Our results show that BMI, weight gain, and omental fat weight are decreased by treatment with the extract. Extract could decrease TG and leptin level in rats under high fat diet, as well. A positive correlation between BMI, leptin, and TG was evident. Treatment with extract could boost total motility and it has a positive effect on sperm abnormal morphology and count. A negative correlation between BMI, leptin, and sperm motility was evident. Sperm abnormal morphology and count were in a positive correlation to serum lipid profile.

Studies investigating the impact of high-fat diet on fertility are controversial (Palmer et al. 2012), however, it is generally concluded that obesity adversely affect sperm parameters and DNA integrity (Kort et al. 2006; Chavarro et al. 2010). Obesity exerts its adverse effects by reducing sex hormone binding globulin (SHBG), decreasing testosterone followed by increased estrogen, and hypothalamic pituitary gonadal (HPG) axis impairment (Palmer et al. 2012).

In our study, rats under high-fat diet showed significantly increased amounts of BMI, TG, and leptin. Considerable reduction in sperm motility in this group was evident, which is in line with other studies (Kort et al. 2006; Sekhavat and Moein 2010; Fernandez et al. 2011), indicating a significant negative correlation between BMI and sperm motility. Increased amounts of TG and TC in high-fat diet group lead to a mitochondrial reactive oxygen, sperm DNA damage, and decreased sperm motility (Koppers et al. 2010; Saez et al. 2011). Adverse effects of the obesity on the male reproduction may be associated with increased levels of TG leading to decreased number of kisspeptin neurons in the arcuate nucleus, which are GnRH-release stimulators (Overgaard et al. 2015). In this study, higher abnormal morphology in the HFD group is in agreement with other studies (Kort et al. 2006; Hofny et al. 2010) indicating a positive correlation between the abnormal morphology and BMI. In our study, a positive correlation between TG, HDL, and LDL, and sperm abnormal morphology was evident, which has also been indicated by Liu et al. (2017). In contrast, Louei Monfared (2013) did not report a significant correlation between TG, HDL, and LDL, and sperm abnormal morphology.

In this study, although GC100 treatment significantly decreased the abnormal morphology of sperm compared to HFD group, it is still significantly increased compared to control group. In case of sperm count, HFD itself increased the sperm count compared to the control group and only GC100 significantly increased the sperm count compared to control, but not compared to HFD. In this study, it can be concluded that although groups containing high fat diet show increased sperm count compared to control group, it is associated with increased abnormal morphology indicating increased sperm count at the cost of abnormal morphology-increased sperm count and increased sperm abnormal morphology.

The inverse correlation between leptin and testosterone levels has been reported (Goncharov et al. 2009). Leptin may function as a direct inhibitory signal for the testicular steroidogenesis, which may be the explanation for the inverse correlation between leptin and testosterone (Tena-Sempere and Barreiro 2002). It has been revealed that the increase of serum leptin decreases testosterone synthesis in Leydig cells, thereby inhibiting sperm maturation and motility (Margetic et al. 2002). It has been concluded that leptin may partly influence the sperm parameters (Hofny et al. 2010). In this study, leptin 
level was decreased significantly when rats were under the high-fat diet treated with GC extract. The following ameliorating effects of extract on sperm motility could be a result of the reduced leptin level. Glycyrrhiza Glabra contains Licorice flavonoid oil (LFO), which decreases the size of the hepatic lipid droplets, which are mainly composed of TG, and abdominal adipose tissue (Aoki et al. 2007), which is also evident in our study that the extract decreases $\mathrm{BMI}$ and omental fat significantly. Enzymatic activities of acetyl-coenzyme A carboxylase (ACA) and fatty acid synthase (FAS), as enzymes of the fatty acid synthesis, are decreased by LFO. In contrast, the enzymatic activity of acyl-coenzyme A dehydrogenase (ACD), as an oxidation enzyme of fatty acid, is increased by LFO. Therefore, LFO regulates synthesis and oxidation of fatty acids by decreasing the TG levels (Kamisoyama et al. 2008).

Studies have reported an inverse correlation between dose of GC or Licorice and the weight gain, presenting higher weight loss caused by higher doses of Licorice (Kamisoyama et al. 2008; Malik and Sharma 2011). Our results are in line with these studies. Our study shows that higher dose of Licorice $(100 \mathrm{mg} / \mathrm{kg}$ ) leads to a better weight loss (lower weight gain) or BMI reduction compared to lower dose of Licorice $(50 \mathrm{mg} / \mathrm{kg})$ in a long-term administration of the Licorice extract.

However, other studies have reported decreased serum testosterone levels by high levels of Licorice (Sakamoto and Wakabayashi 1988; Armanini et al. 1999). The probable mechanism is through glycyr- rhizic acid, one of the active components of Licorice, which impairs the conversion of androstenedione to testosterone through interference with $17 \beta$-hydroxysteroid dehydrogenase - catalyzer of the androstenedione-to-testosterone conversion (Fukui et al. 2003). In addition, it has been reported that decreased serum testosterone level contributes to the insulin resistance, which can contribute to the obesity (Kahn and Flier 2000). Therefore, higher doses of Licorice (more than $100 \mathrm{mg} / \mathrm{kg}$ ) is not recommended.

Both doses of the extract exert their ameliorating effects on the sperm parameters by reducing the BMI, omental fat, weight gain, TG, and leptin level. Although there are some differences between the effects of different doses of the extract, no significant difference was evident, except for leptin level, which was significantly reduced by $50 \mathrm{mg} / \mathrm{kg}$ dose of extract. However, the effect of $100 \mathrm{mg} / \mathrm{kg}$ dose of extract on the sperm parameters was more significant than 50 $\mathrm{mg} / \mathrm{kg}$ dose of extract. Further studies considering the alterations of sex hormones and the histological investigations of testis tissue are required.

\section{Acknowledgements}

Our deep gratitude goes to the anatomical department of Zanjan University of Medical Sciences for cooperation in this project and Metabolic Disease Research Centre of Zanjan University of Medical Sciences, which supported this project (grant number: A-12-302-4).

\section{References}

Aoki F, Honda S, Kishida H, Kitano M, Arai N, Tanaka H, Yokota S, Nakagawa K, Asakura T, Nakai Y, Mae T. Suppression by licorice flavonoids of abdominal fat accumulation and body weight gain in high-fat diet-induced obese C57BL/6J mice. Biosci Biotechnol Biochem 71, 206-214, 2007.

Armanini D, Bonanni G, Palermo M. Reduction of serum testosterone in men by licorice. N Engl J Med 341, 1158, 1999.

Bakos HW, Henshaw RC, Mitchell M, Lane M. Paternal body mass index is associated with decreased blastocyst development and reduced live birth rates following assisted reproductive technology. Fertil Steril 95, 17001704, 2011.

Bibiloni MD, Salas R, De la Garza YE, Villarreal JZ, Sureda A, Tur JA. Serum lipid profile, prevalence of dyslipidaemia, and associated risk factors among Northern Mexican adolescents. J Pediatr Gastroenterol Nutr 63, 544-549, 2016.

Chavarro JE, Toth TL, Wright DL, Meeker JD, Hauser R. Body mass index in relation to semen quality, sperm DNA integrity, and serum reproductive hormone levels among men attending an infertility clinic. Fertil Steril 93, 2222-2231, 2010.

Fernandez CD, Bellentani FF, Fernandes GS, Perobelli JE, Favareto AP, Nascimento AF, Cicogna AC, Kempinas WD. Diet-induced obesity in rats leads to a decrease in sperm motility. Reprod Biol Endocrinol 9, 32, 2011.

Fukui M, Kitagawa Y, Nakamura N, Yoshikawa T. Glycyrrhizin and serum testosterone concentrations in male patients with type 2 diabetes. Diabetes Care 26, 2962, 2003. 
Ghanayem BI, Bai R, Kissling GE, Travlos G, Hoffler U. Diet-induced obesity in male mice is associated with reduced fertility and potentiation of acrylamide-induced reproductive toxicity. Biol Reprod 82, 96-104, 2010.

Goncharov NP, Katsya GV, Chagina NA, Gooren LJ. Testosterone and obesity in men under the age of 40 years. Andrologia 41, 76-83, 2009.

Hofny ER, Ali ME, Abdel-Hafez HZ, Kamal Eel-D, Mohamed EE, Abd El-Azeem HG, Mostafa T. Semen parameters and hormonal profile in obese fertile and infertile males. Fertil Steril 94, 581-584, 2010.

Kahn BB, Flier JS. Obesity and insulin resistance. J Clin Invest 106, 473-481, 2000.

Kamisoyama H, Honda K, Tominaga Y, Yokota S, Hasegawa S. Investigation of the anti-obesity action of licorice flavonoid oil in diet-induced obese rats. Biosci Biotechnol Biochem 72, 3225-3231, 2008.

Kaur R, Kaur H, Dhindsa AS. Glycyrrhiza glabra: a phytopharmacological review. Int J Pharm Sci Res 4, 2470-2477, 2013.

Kelishadi R, Hashemipour M, Sheikh-Heidar A, Ghatreh-Samani S. Changes in serum lipid profile of obese or overweight children and adolescents following a lifestyle modification course. ARYA Atheroscler 8, 143-148, 2012.

Kelly T, Yang W, Chen CS, Reynolds K, He J. Global burden of obesity in 2005 and projections to 2030. Int J Obes (Lond) 32, 1431-1437, 2008.

Khanahmadi MM, Naghdi Badi H, Akhondzadeh S, Khalighi-Sigaroodi F, Mehrafarin A, Shahriari S, Hajiaghaee R. A review on medicinal plant of Glycyrrhiza glabra L. J Med Plant 2, 1-12, 2013.

Kim JH, Hahm DH, Yang DC, Kim JH, Lee HJ, Shim I. Effect of crude saponin of Korean red ginseng on high-fat diet-induced obesity in the rat. J Pharmacol Sci 97, 124-131, 2005.

Koppers AJ, Garg ML, Aitken RJ. Stimulation of mitochondrial reactive oxygen species production by unesterified, unsaturated fatty acids in defective human spermatozoa. Free Radic Biol Med 48, 112-119, 2010.

Kort HI, Massey JB, Elsner CW, Mitchell-Leef D, Shapiro DB, Witt MA, Roudebush WE. Impact of body mass index values on sperm quantity and quality. J Androl 27, 450-452, 2006.

La Vignera S, Condorelli RA, Vicari E, Calogero AE. Negative effect of increased body weight on sperm conventional and nonconventional flow cytometric sperm parameters. J Androl 33, 53-58, 2012.

Liu CY, Chou YC, Lin SH, Wu ST, Cha TL, Chen HI, Tsao CW. Serum lipid profiles are associated with semen quality. Asian J Androl 19, 633-638, 2017.

Louei Monfared A Correlation of serum lipid profile with histological and seminal parameters of testis in the goat. Int J Fertil Steril 7, 122-129, 2013.

Malik ZA, Sharma PL. An ethanolic extract from Licorice (Glycyrrhiza glabra) exhibits anti-obesity effects by decreasing dietary fat absorption in a high fat diet-induced obesity rat model. IJPSR 2, 3010-3018, 2011.

Margetic S, Gazzola C, Pegg GG, Hill RA. Leptin: a review of its peripheral actions and interactions. Int J Obes Relat Metab Disord 26, 1407-1433, 2002.

Mitchell NS, Catenacci VA, Wyatt HR, Hill JO. Obesity: overview of an epidemic. The Psychiatr Clin North Am 34, 717-732, 2011.

Momeni HR, Eskandari N. Effect of vitamin E on sperm parameters and DNA integrity in sodium arsenite-treated rats. Iran J Reprod Med 10, 249-256, 2012.

Monton A, Gil L, Malo C, Olaciregui M, Gonzalez N, de Blas I. Sage (Salvia officinalis) and fennel (Foeniculum vulgare) improve cryopreserved boar epididymal semen quality study. Cryo Letters 36, 83-90, 2015.

Namazi N, Alizadeh M, Mirtaheri E, Farajnia S. The effect of dried Glycyrrhiza Glabra L. extract on obesity management with regard to PPAR- $\gamma 2$ (Pro12Ala) gene polymorphism in obese subjects following an energy restricted diet. Adv Pharm Bull 7, 221-228, 2017.

Nejatbakhsh R, Riyahi S, Farrokhi A, Rostamkhani S, Mahmazi S, Yazdinezhad A, Kazemi M, Shokri S. Ameliorating effects of fennel and cumin extracts on sperm quality and spermatogenic cells apoptosis by inducing weight loss and reducing leptin concentration in diet-induced obese rats. Andrologia 49, 2017.

Overgaard A, Axel AM, Lie ME, Hansen HH, Mikkelsen JD. High plasma triglyceride levels strongly correlate with low kisspeptin in the arcuate nucleus of male rats. Endocr Regul 49, 51-57, 2015.

Palmer NO, Bakos HW, Fullston T, Lane M. Impact of obesity on male fertility, sperm function and molecular composition. Spermatogenesis 2, 253-263, 2012.

Rahimi R, Ardekani MR. Medicinal properties of Foeniculum vulgare Mill. in traditional Iranian medicine and modern phytotherapy. Chin J Integr Med 19, 73-79, 2013.

Saez F, Ouvrier A, Drevet JR. Epididymis cholesterol homeostasis and sperm fertilizing ability. Asian J Androl 13, 11-17, 2011. 
Sakamoto K, Wakabayashi K. Inhibitory effect of glycyrrhetinic acid on testosterone production in rat gonads. Endocrinol Jpn. 35, 333-342, 1988.

Sekhavat L, Moein MR. The effect of male body mass index on sperm parameters. Aging Male 13, 155-158, 2010.

Shokri S, Aitken RJ, Abdolvahhabi M, Abolhasani F, Ghasemi FM, Kashani I, Ejtemaeimehr S, Ahmadian S, Minaei B, Naraghi MA, Barbarestani M. Exercise and supraphysiological dose of nandrolone decanoate increase apoptosis in spermatogenic cells. Basic Clin Pharmacol Toxicol 106, 324-330, 2010.

Sikaris KA. The clinical biochemistry of obesity. Clin Biochem Rev 25, 165-181, 2004.

Struck MB, Andrutis KA, Ramirez HE, Battles AH. Effect of a short-term fast on ketamine-xylazine anesthesia in rats. J Am Assoc Lab Anim Sci 50, 344-348, 2011.

Teerds KJ, de Rooij DG, Keijer J. Functional relationship between obesity and male reproduction: from humans to animal models. Hum Reprod Update 17, 667-683, 2011.

Tena-Sempere M, Barreiro ML. Leptin in male reproduction: the testis paradigm. Mol Cell Endocrinol 188, 9-13, 2002. 